equally in affected males and females, the prognosis differs enormously between the sexes. In men, after a variable latent period, the disease commonly progresses to death from renal failure by the age of 40 , whereas in women it usually pursues a much more benign and not necessarily fatal course. ${ }^{5}$ This pattern of the disease is consistent in the majority of families, but rarely there is a more benign disorder ${ }^{6}$ or more serious lesions in females. ${ }^{7}$

Several extrarenal associations may provide strong confirmation of the diagnosis. Undoubtedly the commonest is nerve deafness, which was recognized originally by A. C. Alport ${ }^{8}$ in 1927. Subsequently the clinical syndrome of nerve deafness and hereditary nephritis has borne his name. The deafness, like the renal lesion, is more severe in the male and is slowly progressive from childhood onwards. The high tone loss which is characteristic of Alport's syndrome may be mild, and it is clear that routine audiometry must be carried out to detect all cases. In some families deafness may be present without the associated renal lesion. Defects of the lens and its capsule ${ }^{10}$ occur in a minority of families, and ophthalmologists encountering such unusual lesions as lenticonus, spherophakia, and juvenile cataracts would do well to inquire of the family history and to carry out tests of renal function.

Examination of renal biopsies or of tissue obtained at necropsy has proved disappointing in that no consistent or diagnostic features have been detected. H. I. Krickstein and his co-workers ${ }^{11}$ have described a mixed type of nephritis with combinations of certain features indistinguishable from those seen in glomerulonephritis, pyelonephritis, and interstitial nephritis. Much has been written about the significance of lipid-staining foam cells. While they appear to be a nonspecific response in chronic renal disease, their frequency in the majority of patients with hereditary nephritis is remarkably high. ${ }^{12}$ Their presence in biopsy material taken in the early stages of disease should draw attention to the possibility of a familial nephritis, though their absence should not preclude the diagnosis. ${ }^{11}$ Electron-microscopy has shown nonspecific changes, with thickening of tubular and glomerular basement membranes, increase in mesangial tissue, and fusion of foot processes. Immunofluorescent techniques have failed to show the deposits typical of many forms of glomerulonephritis. ${ }^{13}$

In most families inheritance is as an autosomal dominant, though earlier workers postulated partial sex-linkage ${ }^{14}$ with preferential segregation ${ }^{15}$ to account for an apparent excess of affected females. One family has been reported showing sexlinked dominant inheritance. ${ }^{16}$ Now that the natural history of hereditary nephritis is fully understood and its sinister course in the male appreciated there is need for full surveys of affected families and appropriate genetic counselling. Unhappily it is likely to prove difficult to dissuade an apparently healthy woman with albuminuria from having children. However, in many families the disease seems to run through only a few generations before dying out. It is of interest that Alport's original family has now been traced and brought up to date, and there is no possibility of further new cases. ${ }^{17}$

Ignorance of the causation of this curious disorder limits therapy, and management is similar to that of other patients with chronic renal failure. Some patients have been treated with steroids or immunosuppressive agents, with no real benefit. Others have been accepted for chronic dialysis regimens, and a few have undergone renal transplantation with initial success. ${ }^{13}$ In the absence of any major advance in detecting a possible error of metabolism our efforts must be directed towards tracing these families and offering sensible genetic advice.

${ }^{1}$ Chazan, J. A., Zacks, J., Cohen, J. J., and Garella, S., American fournal of Medicine, 1971, 50, 764 .

2 Samuelson, F., Virchows Archiv für Pathologische Anatomie, 1874, 59, 257.

3 Moseley, J. H., and Polak, A., Proceedings of the Royal Society of Medicine, $1967,60,246$.

${ }^{4}$ Knepshield, J. H., Roberts, P. L., Davis, C. J., and Moser, R. H., Archives

of Internal Medicine, 1968, $122,156$.
Perkoff, G. T., Annual Review of Medicine, 1964, 15, 115.

- McConville, J.M., M., West, C. D., and McAdams, A. J., fournal of Pediatrics, 1966, 69, 207.

'Albert, M. S., Leeming, J. M., and Wigger, H. J., American Diseases of Childhood, 1969, 117, 153.

8 Alport, A. C., British Medical fournal, 1927, 1, 504.

9 Sohar, E., Archives of Internal Medicine, 1956, 97, 627

10 Arnott, E. J., Crawfurd, M. D'A., and Toghill, P. J., British fournal of Ophthalmology, 1966, 50, 390.

11 Krickstein, H. I., Gloor, F. J., and Balogh, K., Archives of Pathology, 1966, 82, 506 .

12 Whalen, R. E., Huang, S., Peschel, E., and McIntosh, H. D., American Fournal of Medicine, 1961, 31, 171.

13 Chiricosta, A., Jindal, S. L., Metuzals, J., and Koch, B., Canadian Medical Association fournal, 1970, 102, 396

14 Stephens, F. E., Perkoff, G. T., Dolowitz, D. A., and Tyler, F. H.,

American fournal of Human Genetics, 1951,3 , 303.
${ }^{15}$ Shaw, R. F., and Glover, R. A., American fournal of Human Genetics, $1961,13,89$.

${ }^{16}$ Hashimoto, Y., et al., fournal of the fapanese Society of Internal Medicine, $1970,59,1195$.

${ }^{17}$ Crawfurd, M. D'A., and Toghill, P. J., Quarterly fournal of Medicine, 1968, 37, 563.

\section{Pityriasis Lichenoides}

The term parapsoriasis has been used by dermatologists since early in this century and has been the cause of much confusion. L. Brocq ${ }^{1}$ grouped together plaque, lichenoid, and guttate forms, believing they were related conditions, and it was thought they were possible precursors of mycosis fungoides. A. Civatte, ${ }^{2}$ in his classic "Fiftieth Anniversary of Parapsoriasis," considered the guttate forms to be unrelated to the other types, and these are now generally known as pityriasis lichenoides. Two forms (acute and chronic) are recognized, but they are probably different forms of the same disease process.

Pityriasis lichenoides chronica is an uncommon disorder occurring at any age, though most are seen in the first three decades. ${ }^{3}$ It is rather more common in males than females. It presents as widespread, small, scaly papules, the most characteristic feature being a circular scale attached centrally and loose at the periphery which comes away intact on gentle scratching. Though some cases resolve in a few months, especially in children, in the majority crops of lesions erupt over a period of many months or years. The acute form, pityriasis lichenoides et varioliformis acuta or Mucha-Habremann disease, is even less common. It shows much more active papules, red in colour and with a tendency to ulcerate. Some of the lesions are vesicular and some are haemorrhagic. The word acute applies more to the individual lesions than the disease itself as these cases too may persist for many months or years. Acute and chronic lesions are seen together in some patients. Treatment is no more than symptomatic and has little effect on the progress of the disease.

The histological changes in the chronic lesions are relatively slight. There is a perivascular infiltrate in the upper dermis consisting mainly of lymphocytes. The infiltrate may extend into the epidermis, where there is a thick, partly parakeratotic horny layer. ${ }^{4}$ The acute lesions show more severe damage. There is upper dermal oedema, and free red cells are seen in the dermis. The perivascular infiltrate in 
the upper dermis is more intense and some of the deeper dermal vessels are surrounded by inflammatory cells. In a few cases there is more severe vascular damage, which has been interpreted as a vasculitis, ${ }^{5}$ but $\mathbf{R}$. Marks, M. Black, and $\mathrm{E}$. Wilson Jones ${ }^{3}$ do not think that vascular damage has a central role in the pathogenesis of the disease. A curious feature in a few acute cases is the presence of unusually large and bizarre mononuclear cells in the infiltrate, which makes it closely resemble a reticulosis, and indeed two cases are known to have progressed to a true lymphona 6 and ended in death. The name lymphomatoid papulosis has been used for these cases, which were first fully described by V. M. Verallo and J. R. Haserick. ${ }^{7}$ Recently Black and Wilson Jones ${ }^{8}$ have been able to provide details of 15 cases. They are almost certainly variants of pityriasis lichenoides. A few cases have also been reported in association with poikiloderma (lichenoid parapsoriasis), another potentially prereticulotic condition. 9 Nevertheless, the great majority of cases of pityriasis lichenoides are entirely benign and the aetiology remains obscure. There is little evidence of any association with other systemic disease, though 11 of 40 patients tested by Marks and colleagues ${ }^{3}$ showed minor abnormalities of serum protein. These authors also believe the term parapsoriasis has outlived its usefulness and would be better discarded. Many dermatologists would agree with them.

1 Brocq, L., Annales de Dermatologie et de Syphiligraphie, 1902, 3, 313.

2 Civatte, A., Annales de Dermatologie et de Syphiligraphie, 1951, 78, 5 .

3 Marks, R., Black, M., and Jones, E. W., British fournal of Dermatology, $1972,86,215$

4 Lever, W. F., Histopathology of the Skin, 4th edn., p. 170, Philadelphia, J. B. Lippincott, 1967.

5 Szymanski, F. J., Archives of Dermatology, 1959, 79, 7.

- Kawada, A., Anekoji, K., Miyamoto, M., Nakai, T., and Mori, S., Dermatologica, 1969, 138, 369.

7 Verallo, V. M., and Haserick, J. R., Archives of Dermatology, 1966, 94, 295.

8 Black, M. M., and Jones, E. W., British fournal of Dermatology, 1972,

86, 329. Society, 1971, 57, 143.

\section{Pulmonary Veno-occlusive Disease}

Patients with pulmonary hypertension in whom heart disease, chronic lung disease, and thromboembolic disease have been excluded are usually young women with characteristic changes in their pulmonary arterioles but normal pulmonary veins. The condition is termed primary pulmonary hypentension. But 13 case reports have now been published, including two in the last year, ${ }^{12}$ in which the main lesions were intimal thickening and fibrosis of the pulmonary veins. Eight of these patients were male and only four were adults. The youngest died at the age of 8 weeks with changes in the veins which suggested that the disease might have started in utero. ${ }^{2}$

The main clinical features of pulmonary veno-occlusive disease were summarized by C. H. Brown and C. V. Harrison $^{3}$ during the lifetime of their patient, a 40-year-old West Indian physician. These were: a history resembling that of mitral stenosis; clinical signs of pulmonary hypertension; radiological signs of pulmonary oedema without venous distension or inversion of regional flow; and the absence of structural heart disease. The venous lesions were seen in the biopsy and confirmed later at necropsy in $60 \%$ of the veins. ${ }^{4}$ Treatment with injections of heparin $(5,000$ units 6-hourly) was helpful for a time, but the patient died in congestive heart failure with tricuspid incompetence four years after the onset of symptoms. The reported duration of the disease in the 13 cases, all fatal, varied from a month in a boy of 21 months to nine years in a 45-year-old woman, but was less than a year in over half the patients.

The evidence suggests that the venous obstruction is thrombotic in origin. In nine of the 13 cases actual thrombi or recanalization of presumed thrombi were described. Only in the West Indian physician were any clotting studies reported. His platelet adhesiveness was increased by four standard deviations above the normal mean, and platelet survival was short. His fibrinolytic system was normal, with no excessive resistance to streptokinase or urokinase. However, normal pulmonary venous endothelium apparently contains less plasminogen activator than systemic venous endothelium or, for that matter, pulmonary arterial endothelium. ${ }^{5}$ In this respect the pulmonary artery behaves like a systemic vein. It also carries venous blood. If thrombi are being formed and lysed continuously in the vascular system it is possible that toxic or infective agents might, by attacking the pulmonary venous endothelial cells selectively and depleting the plasminogen activator, inhibit lysis and encourage thrombosis, and also cause intimal proliferation. Indeed a virus infection, measles in one case, but non-specific in the others, was reported to have occurred just before or early in the illness in five cases, while in the case thought to have started in utero the mother had had an upper respiratory infection at 34 weeks of pregnancy. Another case had a moderately raised titre of antibodies to Toxoplasmi gondii.

The relationship between pulmonary veno-occlusive disease and the veno-occlusive disease of the liver reported from Jamaica does not appear to be close. Immunofluorescent techniques were used to exclude thrombosis as a factor in veno-occlusive disease of the liver. ${ }^{6}$ Monocrotaline and fulvine, two of the pyrrolizidine alkaloids ingested in Jamaican "bush teas" made from Crotalaria plants and shown to cause veno-occlusive disease of the liver experimentally, have not been shown to cause pulmonary disease in man. Though they have caused pulmonary hypertension in experimental rats, ${ }^{78}$ the lesions are reported to be in the arteries, not in the veins.

Another agent associated epidemiologically with pulmonary hypertension is 2-amino-5-phenyl-2-oxazoline, an appetite-suppressant chemically related to amphetamine, chlorphentermine, and phenmetrazine, which was sold in Switzerland, Germany, and Austria between 1965 and 1968. Again the lesions were arterial rather than venous. So far giving this drug to experimental animals has failed to produce pulmonary hypertension. ${ }^{9-11}$

Recent studies have therefore separated primary pulmonary hypertension into a commoner arterial type and a rarer venous type, distinguishable clinically. Ingested toxic agents are a likely cause of the former, while virus infections seem more likely for the latter.

1 Wagenvoort, C. A., Losekoot, G., and Mulder, E., Thorax, 1971, 26, 429. 2 Heath, D., Scott, O., and Lynch, J., Thorax, 1971, 26, 663.

3 Brown, C. H., and Harrison, C. V., Lancet, 1966, 2, 61.

4 British Medical fournal, 1968, 1, 818.

5 Todd, A. S., Nature, 1958, 181, 495.

- Stirling, G. A., Bras, G., and Urquhart, A. E., Archives of Disease in Childhood, 1962, 37, 535 .

Childhood, 1962, 37, 535. Heath, D., Thorax, 1967, 22, 176.

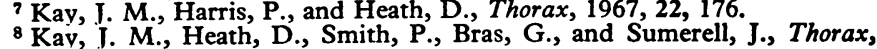
$1971,26,249$.

9 Kav, I. M., Smith, P., and Heath, D., Thorax, 1971, 26, 262.

10 Will, J. A., and Bisgard, G. E., Thorax, 1972, 27, 120.

11 Byrne-Quinn, E., and Grover, R. F., Thorax, 1972, 27, 127. 